\author{
有机或金属-有机二维纳米材料的制备与应用 \\ 李绍周 ${ }^{a} \quad$ 黄晓 $*, b \quad$ 张华 $*, c$ \\ ( ${ }^{a}$ 江苏省有机电子与信息显示重点实验室 南京邮电大学先进材料研究院 南京 210023) \\ ( ${ }^{b}$ 柔性电子重点实验室 先进生物与化学制造协同创新中心 南京工业大学先进材料研究院 南京 211816) \\ ( 材料科学与工程学院 新加坡南洋理工大学 新加坡 639798)
}

\begin{abstract}
摘要 对石墨烯等二维材料的研究进一步引发了人们对相似结构的其他有机、金属一有机二维层状纳米材料的浓厚兴 趣. 这些二维材料由于其优异的化学可剪裁性而受到关注, 预期未来在电子器件、催化和小分子分离等方面具有广泛 的用途. 这篇综述系统地介绍了目前制备有机基二维材料的自上而下和自下而上的两大类方法，总结了有机基二维材 料在生物识别、小分子分离和纯化以及电学方面的应用，最后讨论了有机基二维材料目前在制备和性质改进方面面临 的问题和未来可能发展的研究方向.

关键词 二维材料; 有机晶体; 金属有机骨架材料; 共价有机框架材料
\end{abstract}

\title{
Preparation and Applications of Two-Dimensional Crystals Based on Organic or Metal-Organic Materials
}

\author{
Li, Shaozhou ${ }^{a}$ Huang, Xiao*,b Zhang, Hua ${ }^{*, c}$
}

( ${ }^{a}$ Key Laboratory for Organic Electronics and Information Displays \& Institute of Advanced Materials, Jiangsu National Synergistic Innovation Center for Advanced Materials (SICAM), Nanjing University of Posts \& Telecommunications, Nanjing 210023)

$\left({ }^{b}\right.$ Key Laboratory of Flexible Electronics (KLOFE) \& Institute of Advanced Materials (IAM), Jiangsu National Synergistic Innovation Center for Advanced Materials (SICAM), Nanjing Tech University (NanjingTech), Nanjing 211816)

( ${ }^{c}$ School of Materials Science and Engineering, Nanyang Technological University, Singapore 639798, Singapore)

\begin{abstract}
Besides graphene and transitional metal dichalcogenide nanosheets which have aroused tremendous research interest over the last decade, recently, two-dimensional (2D) organic or metal-organic nanosheets have also attracted increasing research interest. These ultrathin nanomaterials possess the long range structural order, the tunable surface properties, and/or controllable porosity, making them promising in a wide range of applications, such as electronics, optoelectronics, catalysis, molecular separation and so on. This review article aims to provide a brief overview on free-standing 2D nanosheets of organic or metal-organic materials that have been reported so far, especially focusing on their synthetic methods and possible applications.

Keywords two dimensional materials; organic crystals; metal organic frameworks; covalent organic frameworks
\end{abstract}

\section{Introduction}

Since the fabrication of graphene and the demonstration of its outstanding physical properties, ${ }^{[1]}$ two-dimensional (2D) materials have attracted significant attention over the last decade. ${ }^{[2]}$ Various graphene-like 2D inorganic materials, such as metal oxides, ${ }^{[5]}$ metal sulfides ${ }^{[6,7]}$ and metal hydroxides ${ }^{[8]}$ have been prepared and their applications in microelectronics, thermoelectrics, optoelectronics and catalysis have been extensively investigated. ${ }^{[911]}$

Like graphene which could be modified with diversified methods due to the rich carbon-based chemistry, the chemical modification of organic or inorganic-organic hybrid materials is straightforward. ${ }^{[12]}$ To date, various kinds

*E-mail: hzhang@ntu.edu.sg; iamxhuang@njtech.edu.cn; Fax: (+65)67909081

Received March 31, 2015; published May 21, 2015.

This work was supported by MOE under AcRF Tier 2 (ARC 26/13, No. MOE2013-T2-1-034; ARC 19/15, No. MOE2014-T2-2-093) and AcRF Tier 1 (RGT18/13, RG5/13), NTU under Start-Up Grant (M4081296.070.500000) and iFood Research Grant (M4081458.070.500000), Singapore Millennium Foundation in Singapore, and the National Natural Science Foundation of China (GZ213054, 51322202) in China, and the Natural Science Foundation of Jiangsu Province (BK20130927). This research grant is supported by the Singapore National Research Foundation under its Environmental \& Water Technologies Strategic Research Programme and administered by the Environment \& Water Industry Programme Office (EWI) of the PUB. This Research is also conducted by NTU-HUJ-BGU Nanomaterials for Energy and Water Management Programme under the Campus for Research Excellence and Technological Enterprise (CREATE), that is supported by the National Research Foundation, Prime Minister's Office, Singapore.

项目受新加坡教育部基金(ARC 26/13 No. MOE2013-T2-1-034; ARC 19/15, No. MOE2014-T2-2-093; RGT18/13; RG5/13), 新加坡南洋理工大学启动基 金(M4081296.070.500000), 南洋理工大学食品安全科研基金(M4081458.070.500000), 新加坡千禧基金，由新加坡环境与水工业专项办公室(EWI)管 理的环境和水技术国家战略研究计划基金，以及由新加坡总理办公室管理的能源水处理项目(CREATE)基金的支持. 同时，项目受中国国家自然科学 基金(GZ213054; 51322202)以及江苏省自然科学基金(BK20130927)资助. 
of 2D organic or metal-organic materials, such as self-assembled monolayers (SAMs) ${ }^{[13]}$ peptides and their derivatives, ${ }^{[14]}$ metal-organic frameworks (MOFs) ${ }^{[15]}$ covalent-organic frameworks (COFs) ${ }^{[16]}$ and non-porous metal-organic complex nanosheets, ${ }^{[17]}$ have been reported. The long-range structural order, the tunable surface functionality, and the ultrathin nature endow these 2D materials with potential applications in electronics, optoelectronics, catalysis, molecular separation and so on. Although much effort has been made over the past few years, the investigation on the synthesis, characterization and applications of organic or metal-organic 2D materials is still in its infant stage compared to the widely investigated $2 \mathrm{D}$ inorganic nanomaterials.

The organic or metal-organic 2D materials can either be grown or deposited on a flat or curved substrate to form thin film layers, or form free-standing structures stabilized by surface capping molecules or surfactants. The SAM is one of the most representative examples for the former type of materials, which has been reviewed previously. ${ }^{[13,18]}$ Therefore, this review article will only focus on the free-standing 2D nanosheets of organic or metal-organic materials, especially on their synthetic methods and potential applications. Finally the outlook and challenges for future research direction are proposed.

\section{Preparation methods for 2D organic or metal-organic materials}

Similar to many inorganic 2D materials, the preparation methods for 2D organic or metal-organic materials fall into two broad categories, i.e. the top-down and bottom-up approaches. The top-down methods include the liquidphase delamination/exfoliation of bulk crystals, such as layered MOFs or COFs in which the layers are bound by the weak hydrogen bonding or van der Waals interaction. One of the disadvantages of these methods is the lack of precise control over the morphology and thickness of the resulting materials. On the other hand, the bottom-up methods usually include the direct synthesis of $2 \mathrm{D}$ crystals in a physically confined space such as in a soft-template or at the interface of two unmixed media. Although such methods are sometimes complicated, they do show better control over the final product in terms of crystallinity and geometry.

\subsection{Top-down methods}

In the following context, we will discuss the top-down methods based on different starting materials used, namely, layered MOFs, COFs, 2D polymers, and nonporous metal-organic complexes.

\subsubsection{The delamination of layer-structured MOFs}

Within many different hybrid materials that integrate inorganic and organic components, MOFs are a special class of materials with permanent porosity. They are compounds that consist of metal ions or clusters coordinated to rigid or flexible organic molecules to form one-, two-, or three-dimensional $(1 \mathrm{D}, 2 \mathrm{D}$, or $3 \mathrm{D})$ porous structures. ${ }^{[19]}$ Until now, many kinds of MOFs have been reported, including the layer-structured MOFs. Owing to the weak hydrogen bonding or van der Waals interaction between the adjacent layers of layered MOFs, they can be easily intercalated and delaminated in solvents to form $2 \mathrm{D}$ porous nanosheets.

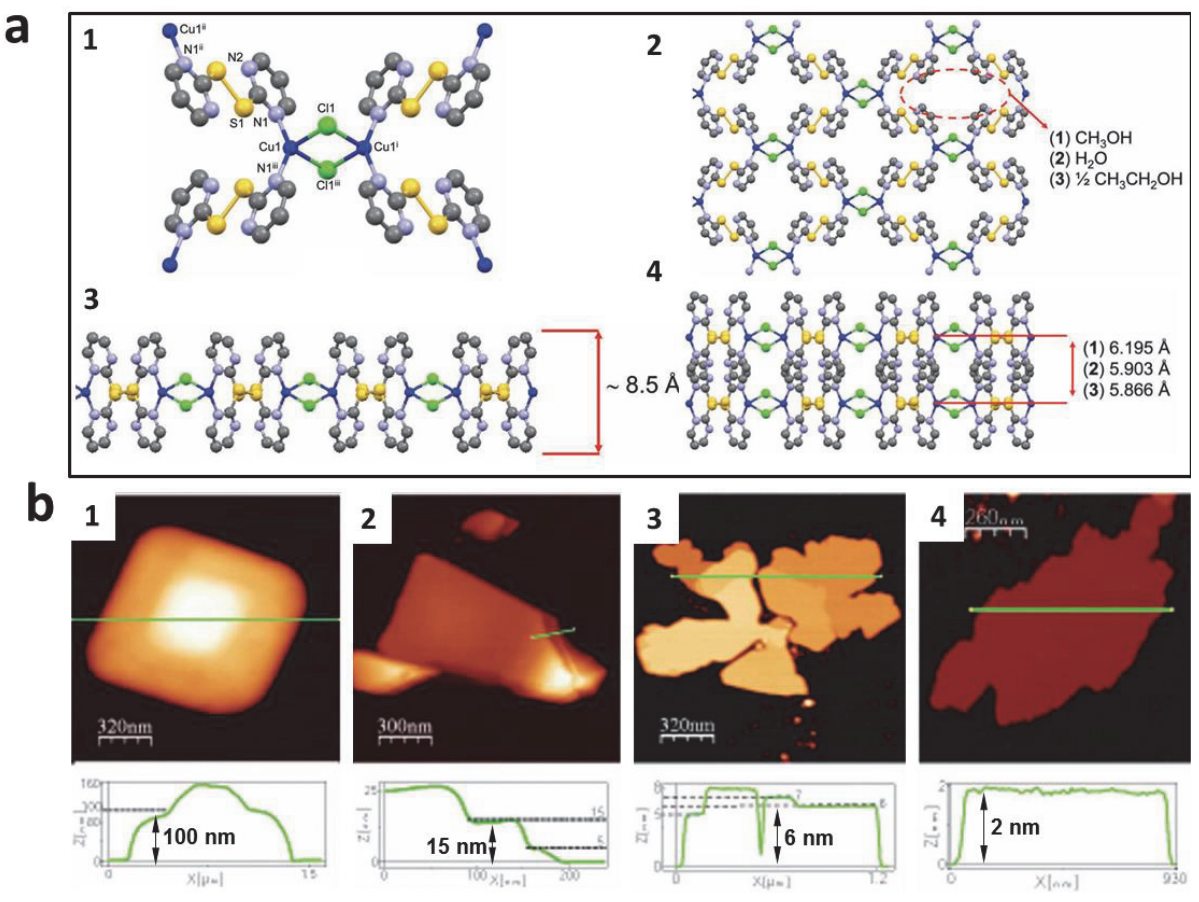

Figure 1 (a) A fragment of crystal structure of the bulk MOF $\left[\mathrm{Cu}\left(\mu-\mathrm{pym}_{2} \mathrm{~S}_{2}\right)(\mu-\mathrm{Cl})\right]_{n} \bullet n \mathrm{Y}$ showing the numbering scheme (1). Perpendicular (2) and side (3) view of the sheet. Pile up of two sheets (4). The hydrogen atoms have been omitted for clarity. (b) Representative AFM topographies on mica and heights profiles of exfoliated crystals treated with water at different time: $1 \mathrm{~d}$ (1), $2 \mathrm{~d}$ (2), $3 \mathrm{~d}$ (3) and 4 d (4). Reproduced with permission from Ref. [20]. Copyright 2013, John Wiley \& Sons, Inc. 
For example, the laminar MOF $\left[\mathrm{Cu}\left(\mu-\operatorname{pym}_{2} \mathrm{~S}_{2}\right)(\mu-\right.$ $\mathrm{Cl})]_{n} \bullet n \mathrm{Y}$ (Figure 1a), where $\mathrm{Y}$ is $\mathrm{MeOH}, \mathrm{H}_{2} \mathrm{O}$ or $1 / 2 \mathrm{EtOH}$, can be fully delaminated by immersion of the bulk MOF crystals in water. ${ }^{[20]}$ Atomic force microscope (AFM) characterization revealed a thickness evolution of the delaminated layers with time, from a mean thickness of 100 $\mathrm{nm}$ after 1 day-incubation to less than $4 \mathrm{~nm}$ after 4 day-incubation (Figure 1b). Similarly, another kind of layered MOF, i.e. $\left\{\mathrm{Zn}(\mathrm{TPA})\left(\mathrm{H}_{2} \mathrm{O}\right) \cdot \mathrm{DMF}\right\}_{n}(\mathrm{MOF}-2)$, has been delaminated in acetone with the assistance of ultrasonication at room temperature. ${ }^{[21]}$ As the bulk MOF-2 crystal is constructed from neutral layers connected by hydrogen bonding with intercalated water molecules, the mechanical forces induced by ultrasonication can easily disrupt the hydrogen bonding between the layers, giving rise to isolated MOF-2 nanosheets, with thicknesses in the range of $1.5 \sim 6.0 \mathrm{~nm}$. Note that the exfoliated nanosheets should be dried before further analysis or process to prevent re-formation of hydrogen bonding between them.

The exfoliation of MOF materials, as similar to that of many layered inorganic crystals, ${ }^{[9,22]}$ is solvent dependent. For example, it was found that the delamination of $\mathrm{Zn}\left(\mathrm{C}_{12} \mathrm{H}_{14} \mathrm{O}_{4}\right)$ can be realized with acetone or ethanol as the solvent, while little delamination occurred in toluene or 2-propanol and no delamination was observed in hexane, formamide, $\quad N, N$-dimethylformamide (DMF) or 1-butanol. ${ }^{[23]}$ This implies that to exert a strong intercalation effect on the layered $\mathrm{Zn}\left(\mathrm{C}_{12} \mathrm{H}_{14} \mathrm{O}_{4}\right)$, small and highly polar solvent molecules are required.

\subsubsection{The exfoliation of layer-structured COFs}

COFs are lightweight, crystalline porous materials that contain well-defined, predictable 2D or 3D ordered porous architectures formed by strong covalent linkages between C, Si, B, N and O. ${ }^{[24]}$ Similar to MOFs, some COF materials are also layer-structured, and therefore they can be exfoliated to give free-standing COF nanosheets.

Zamora and coworkers investigated the exfoliation of COF crystals by direct ultrasonication. ${ }^{[25,26]}$ Several COFs, such as COF-8, CMP-0, CMP-1, CMP-2 and CMP-3, have been successfully delaminated in $\mathrm{CH}_{2} \mathrm{Cl}_{2}$. Inspired by Zamora's work, Bunck et al. reported the synthesis and exfoliation of another COF, i.e. COF-43, which was first synthesized under solvothermal conditions and then ultrasonicated in dioxane to produce COF-43 nanosheets. ${ }^{[27]}$ The obtained nanosheets showed an average height of $1.3 \mathrm{~nm}$, corresponding to $3 \sim 5$ layers of COF-43. Moreover, by replacing the solvent from dioxane to $\mathrm{H}_{2} \mathrm{O}$, double- or even single-layer COF-43 was achieved.

Apart from ultrasonication, mechanical grinding is another top-down method to prepare COF nanosheets. A series of thermally and chemically stable COFs, e.g. $\mathrm{TpPa}_{\mathrm{NO}}, \quad \mathrm{TpPa}-\mathrm{F}_{4}, \quad \mathrm{TpBD}-\left(\mathrm{NO}_{2}\right)_{2}, \quad \mathrm{TpBD}-\mathrm{Me}_{2}$, and TpBD-(OMe) $)_{2}$, were pre-synthesized by using the solvothermal aldehyde-amine Schiff base condensation reaction, ${ }^{[28]}$ and then in turn delaminated by mechanical grinding in the presence of a trace amount of methanol which functioned as the lubricant. The obtained nanosheets showed lateral dimensions of several micrometers and thickness ranging from 3 to $10 \mathrm{~nm}$, which corresponds to ca. 10 30 COF layers.

\subsubsection{The delamination of other polymers}

Recently, 2D synthetic polymers have been reported by several groups. For example, Kissel and colleagues have synthesized poly (fantrip) via a single-crystal-to-singlecrystal photopolymerization process. ${ }^{[29]}$ After this synthetic polymer (Figure 2a) was immersed in 1-methyl-2pyrrolidone (NMP) at room temperature, they became swelled and delaminated quickly. Under further ultrasonication, the swelled polymer crystals were exfoliated into nanosheets with varying thicknesses ranging from 3 to 40 $\mathrm{nm}$ (Figures 2b, 2c). Similarly, another 2D synthetic polymer was achieved through photopolymerization of monomer $\mathbf{1}$ as shown in Figure 2d, and its exfoliation was also carried out in NMP but at an elevated temperature (e.g. $\left.150{ }^{\circ} \mathrm{C}\right) .{ }^{[30]}$ AFM analysis revealed that the obtained nanosheets were $c a .2 .5 \mathrm{~nm}$ thick (Figures $2 \mathrm{e} \sim 2 \mathrm{~g}$ ), in good agreement with the thickness expected for an individual monolayer (Figure $2 \mathrm{~h}$ ).

Besides the synthetic polymers, the exfoliation of non-porous metal-organic complex materials with layered structures has also been demonstrated recently. ${ }^{[31 \sim 34]}$ For example, transition metal frameworks linked by either the meso or chiral $D$ and $L$ isomers of the 2,3-dimethylsuccinate (2,3-DMS) ligand were synthesized by Saines et $a l$. and the liquid exfoliation of these layered crystals to obtain the corresponding nanosheets via ultrasonication was demonstrated. ${ }^{[31,32]}$ In another report, the $2 \mathrm{D}$ nanosheets of copper 5-(2-bromothienyl) phosphonate were prepared by ultrasonication conducted in an aqueous solution. $^{[34]}$ AFM measurement indicated that the nanosheet has lateral dimension of $0.2 \sim 0.5 \mathrm{~mm}$ and almost uniform thickness of $3.2 \sim 3.4 \mathrm{~nm}$ which is comparable to the calculated thickness of a two-layer overlapped stack (i.e. ca. $3.12 \mathrm{~nm}$ ). Besides transitional metals, the synthesis of rare earth metal-organic nanosheets has also been reported. The lanthanide organophosphonate nanosheets were obtained by exfoliation of bulk lanthanum 1,3,5-benzenetriphosphonate (LBP-II), ${ }^{[35]}$ which was first synthesized by a hydrothermal process, and then exfoliated in solvent like DMF to break the interlayer hydrogen bonding, giving rise to nanosheets with varying thicknesses of $1.3 \sim 10 \mathrm{~nm}$. By using the similar exfoliation method, europium and terbium-doped LBP-II nanosheets were also achieved, which showed photoluminescence in green and red, respectively. ${ }^{[36]}$

\subsection{Bottom-up methods}

To date, several bottom-up methods have been reported to prepare $2 \mathrm{D}$ materials of organic or metal-organic materials, including the interfacial method, template-assisted method, and direct wet-chemical synthesis.

\subsubsection{Interfacial synthesis of $2 \mathrm{D}$ materials}

To promote the in-plane growth of $2 \mathrm{D}$ materials with long length, the air-liquid interface was used as an excellent platform for the assembly/growth of 2D materials. ${ }^{[15,37 \sim 44]}$ Recently, by using the LangmuirBlodgett (LB) method together with the layer-by-layer deposition (LB-LbL), nanofilms of MOFs have been prepared on substrates via the interfacial reaction. ${ }^{[15,37 \sim 40]}$ Taking the preparation of NAFS-based MOF as an 

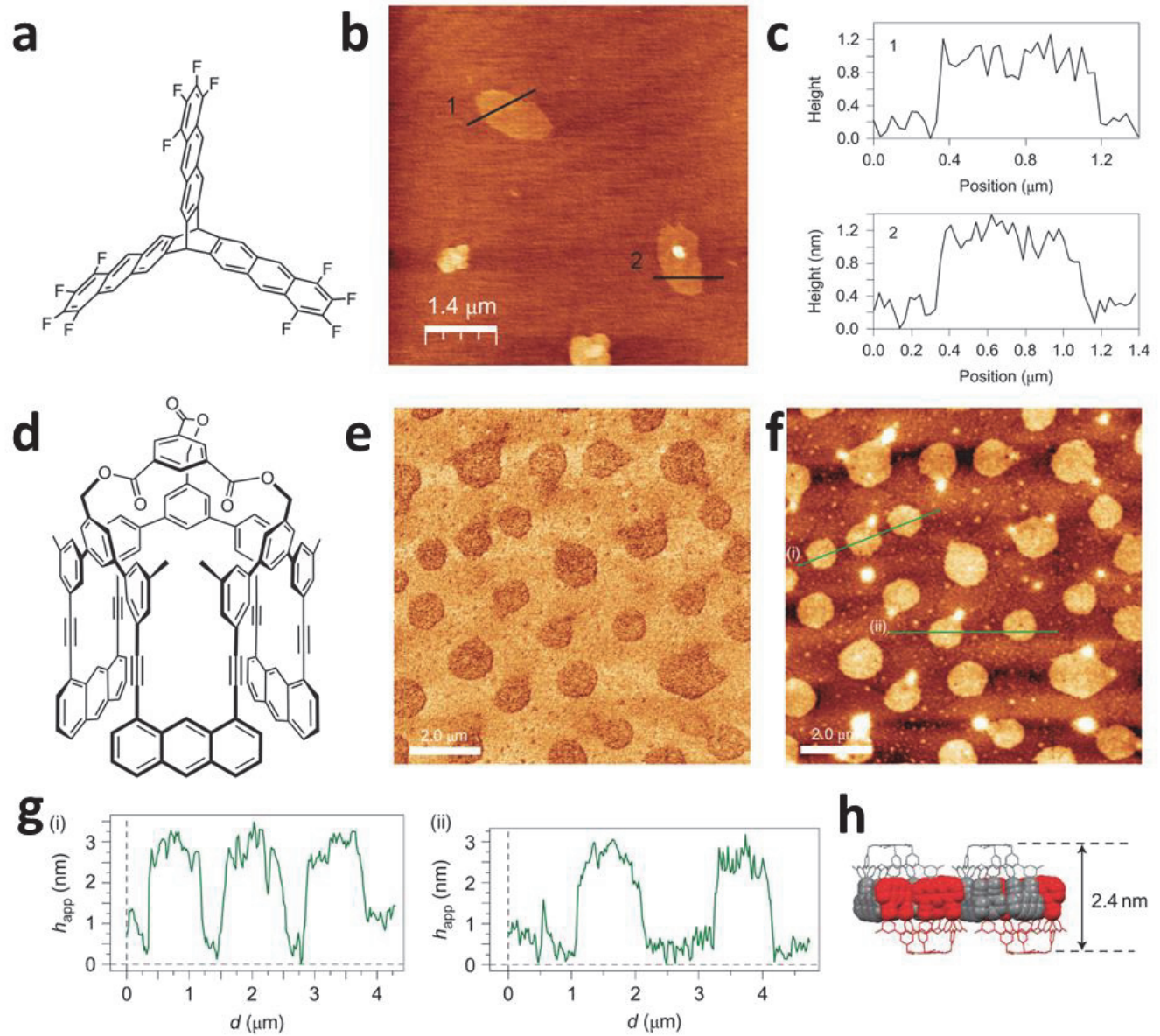

h

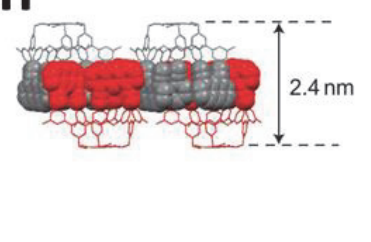

Figure 2 (a) The chemical structure of monomer fantrip. (b) AFM image and (c) height analysis of the exfoliated poly(fantrip) sheets after being soaked in NMP at $50{ }^{\circ} \mathrm{C}$ for 6 days. Reproduced with permission from Ref. [29]. Copyright 2014, Nature Publishing Group. (d) The chemical structure of monomer 1. AFM (e) phase and (f) height images of fully exfoliated sheets on mica after heating the irradiated crystals at $150{ }^{\circ} \mathrm{C}$ in $\mathrm{NMP}$ for 3 days. (g) Height analysis versus distance along the green lines (i and ii) in the image (f) shows a uniform thickness of ca. $2.5 \mathrm{~nm}$, in good agreement with the thickness expected for an individual monolayer (h). Reproduce with permission from Ref. [30]. Copyright 2012, Nature Publishing Group.

example, briefly, a solution containing the molecular building units (e.g. trans- $\mathrm{H}_{2} \mathrm{DCPP}$ or $\mathrm{H}_{2}$ TCPPTE) in a consolable solvent is spread onto an aqueous solution containing the subphase of metal ions $\left(e . g . \mathrm{Cu}^{2+}\right)$ at the air-water interface, where the molecular building blocks coordinate with the metal ions to form the layered structure owing to the LB film assemblies (Figure 3a). ${ }^{[41]}$ The thickness of the layered structure can be further increased with the repeated cycles of LbL deposition. With this method, nanosheets of a series MOF materials, including NAFS-1, NAFS-2, NAFS-13, NAFS-31 and NAFS-41, have been prepared. Note that the MOF nanosheets are too thin to give detectable lattice information by using normal X-ray diffraction (XRD). Therefore, the grazing-incidence synchrotron X-ray diffraction (GIXRD) was used for the structural characterization, which suggested that these NAFS nanosheets possess excellent lateral crystalline order and are highly textured (Figures $3 b \sim 3 e$ ).

In addition to MOF nanosheets, Zuckermann et al. reported the 2D assembly of a sequence-specific peptoid polymer (Peptoid 1, Figure 4a) via the electrostatic interaction at an air-water interface or oil-water interface. ${ }^{[43]}$ AFM analyses of individual peptoid nanosheets revealed that the nanosheets exhibited a thickness of $(3.0 \pm 0.3) \mathrm{nm}$ which is consistent with a 2-molecule-thick bilayer (Figure 4b). Very recently, Payamyar et al. reported the formation of a covalent monolayer sheet through the spreading of three-fold anthracene-equipped shape-persistent and amphiphilic monomers (Figure 4c) at the air-water interface followed by a short photochemical treatment to produce monolayered covalent sheets with thickness of $c a .1 .7 \mathrm{~nm}$ (Figure 4d). ${ }^{[4]}$

\subsubsection{Templated-synthesis of $2 \mathrm{D}$ organic materials}

To produce $2 \mathrm{D}$ crystals of organic or metal-organic materials, another very important approach is the template-assisted method based on ordered soft materials, such as SAMs and surfactant micelles.

SAM is a highly ordered single layer of organic molecules chemisorbed on a surface. ${ }^{[18]}$ Recently, Nakano and coworkers reported the synthesis of oxygen-free, monolayered organosilicon nanosheets by using SAM-based soft templates. ${ }^{45,46]}$ For example, the SAM of $[\mathrm{PhMgBr}]$ molecules was first formed on a silicon substrate, and then reacted with further absorbed $\left[\mathrm{Si}_{6} \mathrm{H}_{6}\right]$ to give $\left[\mathrm{Si}_{6} \mathrm{H}_{x} \mathrm{Ph}_{6-x}\right]$ nanosheets, which exhibited thickness of $c a .1 .11 \mathrm{~nm}$, 
comparable to the simulated value for a $\left[\mathrm{Si}_{6} \mathrm{H}_{x} \mathrm{Ph}_{6-x}\right]$ monolayer (i.e. ca. $0.98 \mathrm{~nm}$ ). Additionally, SAMs can also act as sacrificial templates to be converted to $2 \mathrm{D}$ materials via reactions induced by light/electron irradiation. For example, Eck et al. reported the controlled preparation of molecular thick nanosheets through electron-induced crosslinking of SAM precursors (e.g. 1,1'-biphenyl-4-thiol or 4'-nitro-1,1'-biphenyl-4-thiol) followed by the release of the nanosheets from the substrate (e.g. gold or mica). ${ }^{[47]}$

Apart from SAMs, micelle structures from self-assembled surfactants can also act as soft templates to confine the growth of 2D structures. Juggeburth et al. reported the synthesis of 2D zinc coordination polymer [Zn(BeIM)OAc] by the self-assembly of zinc complex into stacked layers interleaved with cethyltrimethylammonium bromide (CTAB) at regular intervals. ${ }^{[48]}$ The hybrid structures with alternating layers of $\mathrm{Zn}$-based polymer and
CTAB have a repeating lattice period of $c a .8 \mathrm{~nm}$ (Figure $5 \mathrm{a}$ ), and the different layers can be separated via direct solvent exfoliation (Figure 5b). ${ }^{[48]}$

\subsubsection{Direct wet-chemical synthesis of 2D materials}

In addition to interfacial synthesis and template-assisted method, 2D organic materials can be directly prepared in solution without pre-assembly of building blocks on a solid surface or at air/liquid interface. ${ }^{[49 \sim 57]}$ For example, Zuckermann and coworkers designed the peptoid sequences (Nae-Npe $)_{18}$ and (Nce-Npe) $)_{18}$ (Figure 6a), which assembled into free-floating 2D nanosheets via the electrostatic attraction when they were mixed in a $1: 1$ ratio in aqueous buffer. $^{[49 \sim 51]}$ The peptoid nanosheets span tens to hundreds of micrometers in lateral dimensions with uniform thickness of $2.7 \mathrm{~nm}$ (Figure 6b), corresponding to a bilayer of $(\mathrm{Nae}-\mathrm{Npe})_{18}$ and $(\mathrm{Nce}-\mathrm{Npe})_{18}$.
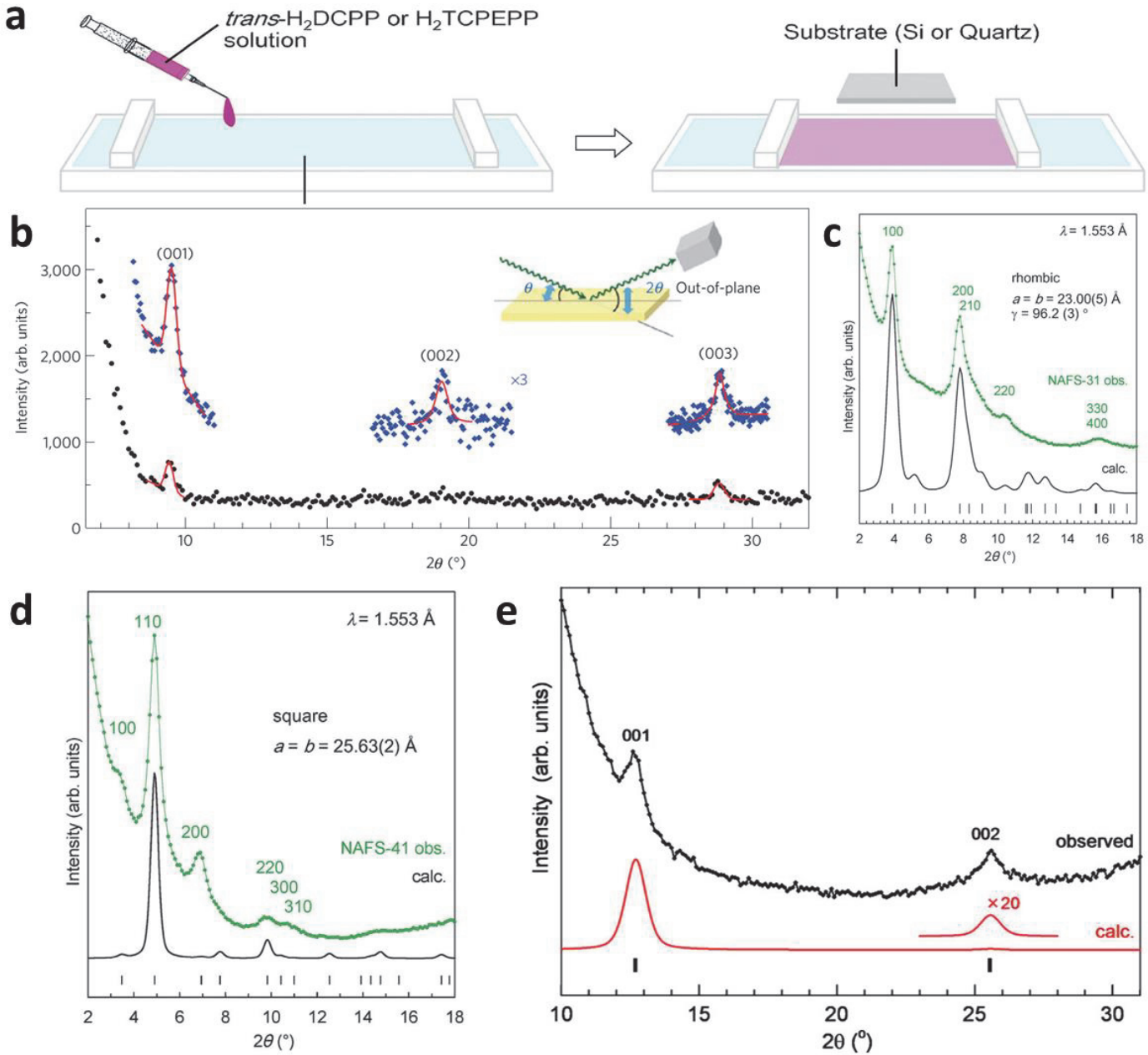

Figure 3 (a) Schematic image of the assembly process of trans-DCPP-Cu (NAFS-31) and TCPEPP-Cu (NAFS-41) nanosheets at the air/liquid interface. The solution of trans $-\mathrm{H}_{2} \mathrm{DCPP}$ or $\mathrm{H}_{2}$ TCPEPP molecular building units was spread onto the aqueous solution of $\mathrm{Cu}\left(\mathrm{NO}_{3}\right)_{2} \cdot 3 \mathrm{H}_{2} \mathrm{O}$ in a Langmuir trough. The surface pressure was controlled by the surface compression of double-sided barriers and was kept constant during deposition onto the solid substrates. Reproduced with permission from Ref. [40] Copyright 2014, John Wiley \& Sons, Inc. (b) Out-of-plane GIXRD pattern of NAFS-1. Reproduced with permission from Ref. [15], Copyright 2010, Nature Publishing Group. (c) Out-of-plane GIXRD pattern of NAFS-31. Reproduced with permission from Ref. [37]. Copyright 2010, John Wiley \& Sons, Inc. (d) Out-of-plane GIXRD pattern of NAFS-41. Reproduced with permission from Ref. [38]. Copyright 2011, American Chemical Society. (e) Out-of-plane GIXRD pattern of NAFS-2. Reproduced with permission from Ref. [40]. Copyright 2014, John Wiley \& Sons, Inc. 

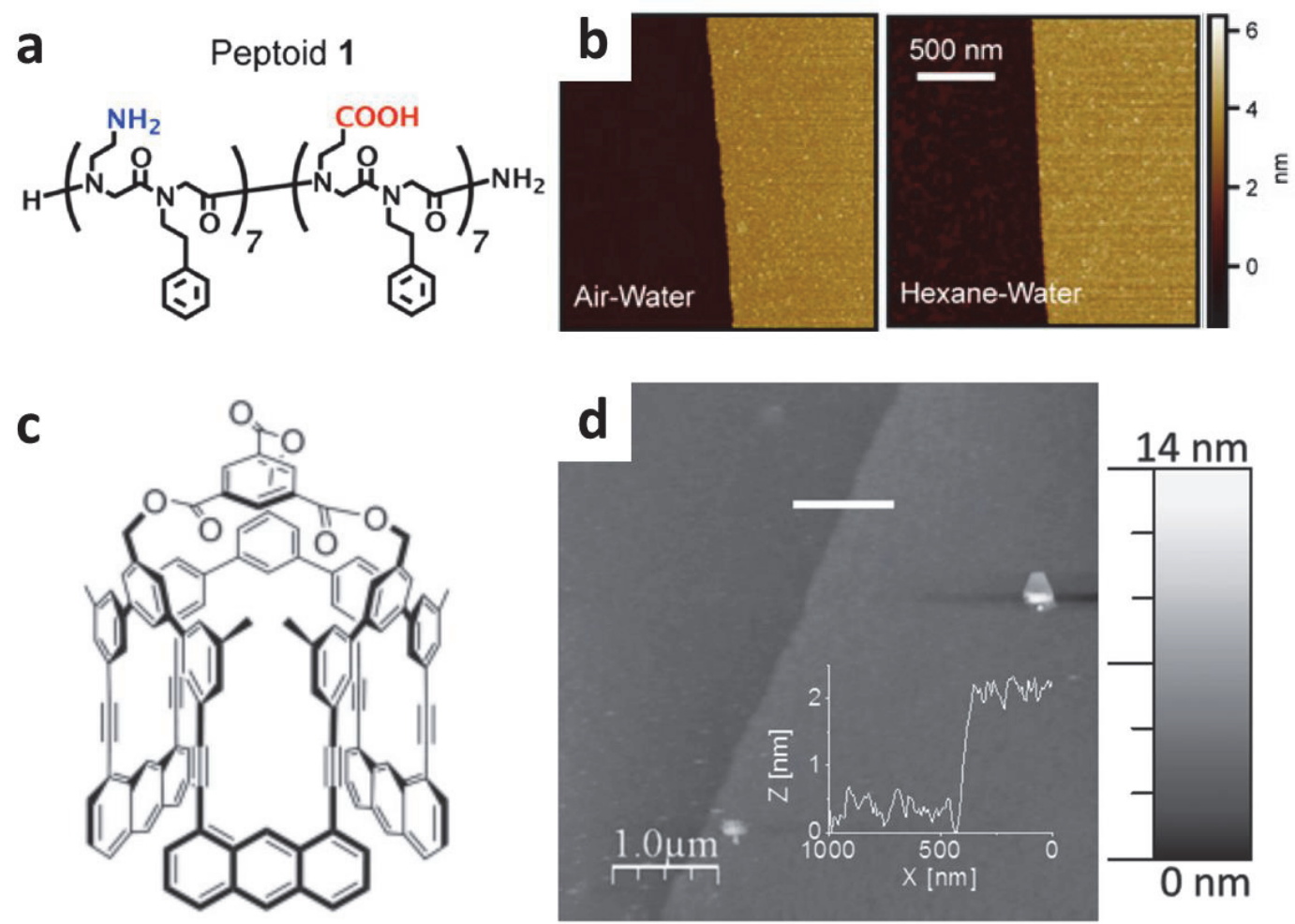

Figure 4 (a) Chemical structure of peptoid 1. (b) AFM image of the edge of an individual peptoid nanosheet deposited on a mica substrate. Reproduced with permission from Ref. [43]. Copyright 2014, American Association for the Advancement of Science. (c) Chemical structure of the shape-persistent trifunctional monomer. (d) Tapping mode AFM height image of the non-polymerized monolayer after transfer onto a silicon wafer. Inset: Height profile indicating a film thickness of $c a .1 .7 \mathrm{~nm}$. Reproduced with permission from Ref. [44]. Copyright 2013, John Wiley \& Sons, Inc.
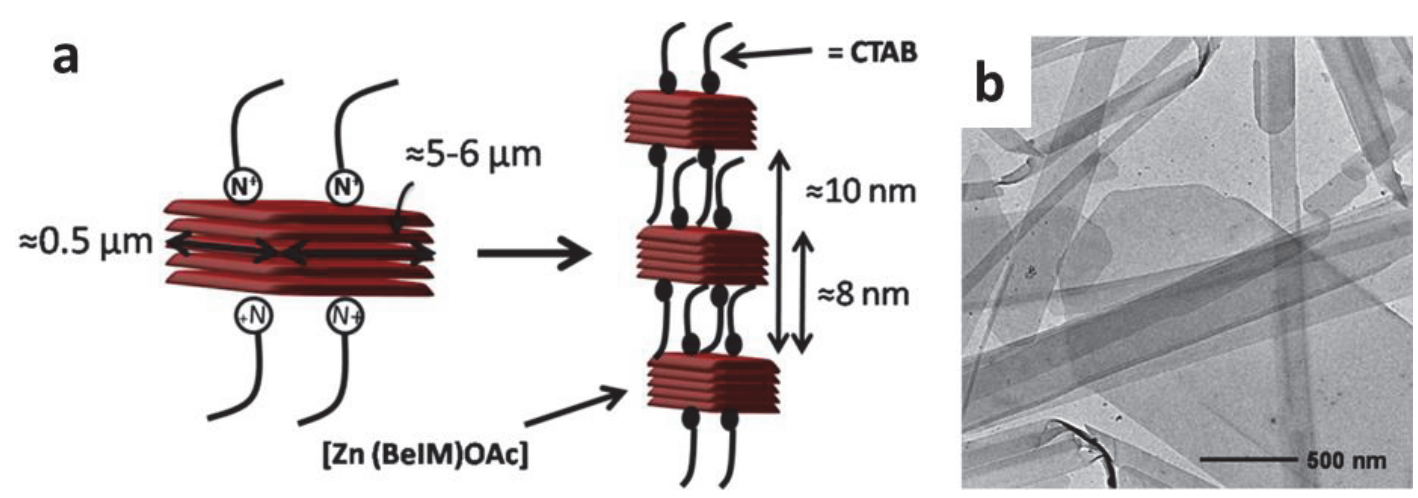

Figure 5 (a) Composite mesostructure of BeIM-MIF, composed of layers of [Zn(BeIM)OAc] (in red) stacked along [001], and separated at regular intervals by CTAB (black). (b) TEM image of BeIM-MIF sheets exfoliated in THF. Reproduced with permission from Ref. [48]. Copyright 2013, American Chemical Society.

Besides the aforementioned self-assembly via electrostatic interaction, Baek et al. reported a novel approach for synthesis of free-standing, covalently bonded, monomer-thick 2D polymers through a thiol-ene "click" reaction of (allyloxy) ${ }_{12} \mathrm{CB}[6]$ in solution. ${ }^{[54]}$ AFM image revealed that the average thickness of synthesized polymer nanosheets was $(2.0 \pm 0.1) \mathrm{nm}$, which is thicker than that of the calculated value (i.e. $c a .1 .5 \mathrm{~nm}$ ), probably due to the surface absorbed counterions (i.e. $\mathrm{Cl}^{-}$) and possibly a water layer. ${ }^{[55]}$
One of the advantages of direct chemical synthesis is the ability to realize shape controlled preparation of organic 2D structures. For example, one-molecule-thick free-standing cucurbit[8]uril based nanosheets with square shape and uniform thickness of $c a .1 .8 \mathrm{~nm}$ were produced by An et al. Based on their proposed model which was confirmed by XRD and TEM analysis, these nanosheets were constructed from small organic molecules (e.g. quinolone) assembled inside the cavities of cucurbit[8]uril molecules which showed a preferred square-shaped unit 

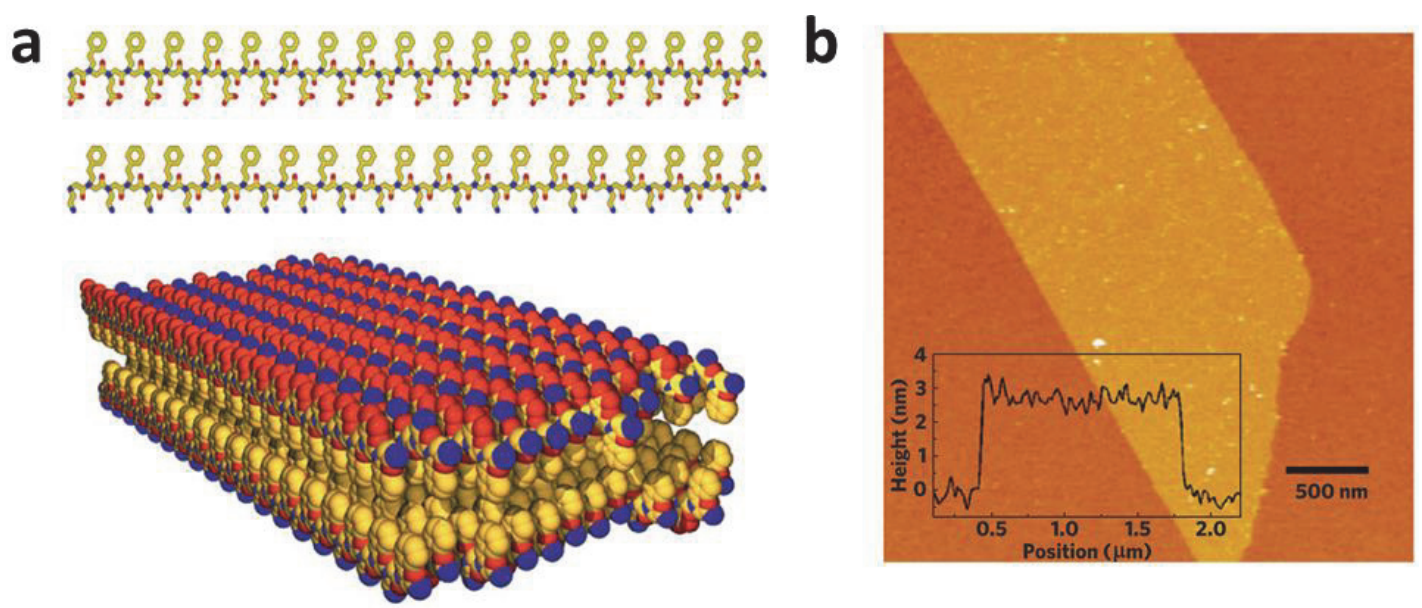

Figure 6. (a) Chemical structure of a negatively charged periodic amphiphilic peptoid, (Nce-Npe) ${ }_{18}$, Chemical structure of a positively charged periodic amphiphilic peptoid, (Nae-Npe) $)_{18}$ and molecular model of the sheets assembled from (Nae-Npe) ${ }_{18}$ and (Nce-Npe) $)_{18}$. (b) AFM image and height analysis of an assembled (Nae-Npe) $)_{18} /(\text { Nce-Npe })_{18}$ sheet. Reproduced with permission from Ref. [49]. Copyright 2014, Nature Publishing Group.

cell. ${ }^{[33]}$ In another report, Zhang and coworkers reported the preparation of well-defined azacalix[6]pyridine (APy6) nanosheets with a triclinic shape in aqueous solution. ${ }^{[56]}$ The synthesis is assisted by selenium containing amphiphile molecules, because they prefer to bind with the APy6 molecules' face packing direction via the non-covalent $\mathrm{Se}-\mathrm{N}$ interaction and thus inhibit the growth in this direction.

\section{Applications of 2D organic materials}

Although many different kinds of free-standing 2D organic or metal-organic materials have been synthesized, the exploration of their applications is still at a very early stage. Currently, these materials are mainly applied in biomolecular recognition, nanoelectronics and gas separation.

\subsection{Biomolecular recognition}

Many 2D organic materials with large planar surfaces can serve as chemically well-defined hydrophilic scaffolds on which biologically active ligands can be loaded for biomolecular recognition. ${ }^{[49]}$ For example, the (Nae-Npe) ${ }_{18}$ peptoid chains mentioned in Section 2.2.3 can be functionalized with streptavidin binding peptide ligand cyclo-[CHPQFC] and then self-assembled into $2 \mathrm{D}$ polymeric nanosheets. Both of the cyclo-[CHPQFC]-bearing nanosheets and those without ligand modification were then mixed with $\mathrm{Cy} 3$-streptavidin and washed with buffer. The cyclo-[CHPQFC] modified nanosheets retained significant $\mathrm{Cy} 3$ fluorescence, whereas the un-functionalized nanosheets had minimal fluorescence (Figure 7a). This demonstrates that a biologically active ligand (e.g. cyclo-[CHPQFC]) can be linked to a sheet-forming peptoid which then undergoes 2D self-assembly. Meanwhile, the ligand displayed on the surface of the nanosheet can specifically bind a protein of interest. The same group later reported that during the formation of peptoid nanosheets at the water-air interface, loopforming sequences, which were specially designed, could be preferentially displayed on the aqueous side of the water-air interface (Figure 7b), and ultimately became the exterior surface of the nanosheet.
Such peptide loop-displaying nanosheets were capable of molecular recognition by enzymes (e.g. proteases and CK2 $\alpha){ }^{[58]}$ Recognition of the peptide substrate by the kinase causes a chemical modification (phosphorylation of the serine residue) of the nanosheets, which can be readily detected with gel electrophoresis (Figure 7c).

\subsection{Nanoelectronics}

Topological insulators are a class of materials exhibiting unique quantum transport properties with potential applications in spintronics and quantum computing. ${ }^{[59]}$ Recently, Wang et al. predicted that 2D network of $\mathrm{Ph}_{3} \mathrm{M}(\mathrm{M}=\mathrm{Pb}$ or $\mathrm{Bi})$ is a potential organic topological insulator. ${ }^{[00]}$ In addition, they identified the first topological insulator based on a 2D organometallic framework which consists of a $\pi$-conjugated nickel-bis-dithiolene with a chemical formula of $\mathrm{Ni}_{3} \mathrm{C}_{12} \mathrm{~S}_{12}$ (Figure $8 \mathrm{a}$ ). ${ }^{[61]}$ The electrical properties of this material were predicted by the first-principle calculation and single-orbital tight-binding model which indicated that it exhibits nontrivial topological states in both a Dirac band and a flat band, therefore confirming it as an organic topological insulator (Figures 8b, 8c). Experimentally, this material was recently synthesized through a coordination reaction between benzenehexathiol (BHT) and nickel(II) acetate $\left[\mathrm{Ni}-(\mathrm{OAc})_{2}\right] \mathrm{c}$ by Kambe and colleagues. ${ }^{[62]}$ Through controlling the oxidation state of this nickel complex nanosheet via chemical oxidation and reduction, the electrical conductivity of this material was evaluated using the van der Pauw method and a very high conductivity of $1.6 \times 10^{2} \mathrm{~S} \cdot \mathrm{cm}^{-1}$ at $300 \mathrm{~K}$ was achieved (Figures $8 \mathrm{~d} \sim$ $8 f) .{ }^{[62]}$

\subsection{Gas separation}

MOF nanosheets can be mixed with polymeric matrices or porous $\mathrm{Al}_{2} \mathrm{O}_{3}$ to make molecular sieve membranes. The preparation of $\mathrm{Zn}_{2}(\mathrm{bim})_{4}$ nanosheets with large lateral area and high crystallinity was reported by Yang's group. ${ }^{[63]}$ These nanosheets were mixed with porous $\alpha-\mathrm{Al}_{2} \mathrm{O}_{3}$ to prepare ultrathin molecular sieve membranes, which achieved a permeance for hydrogen gas $\left(\mathrm{H}_{2}\right)$ of up to several thousand gas permeation units (GPUs), and $\mathrm{H}_{2} / \mathrm{CO}_{2}$ selectivity greater than 200 (Figure 9a 9b). By suppressing the 

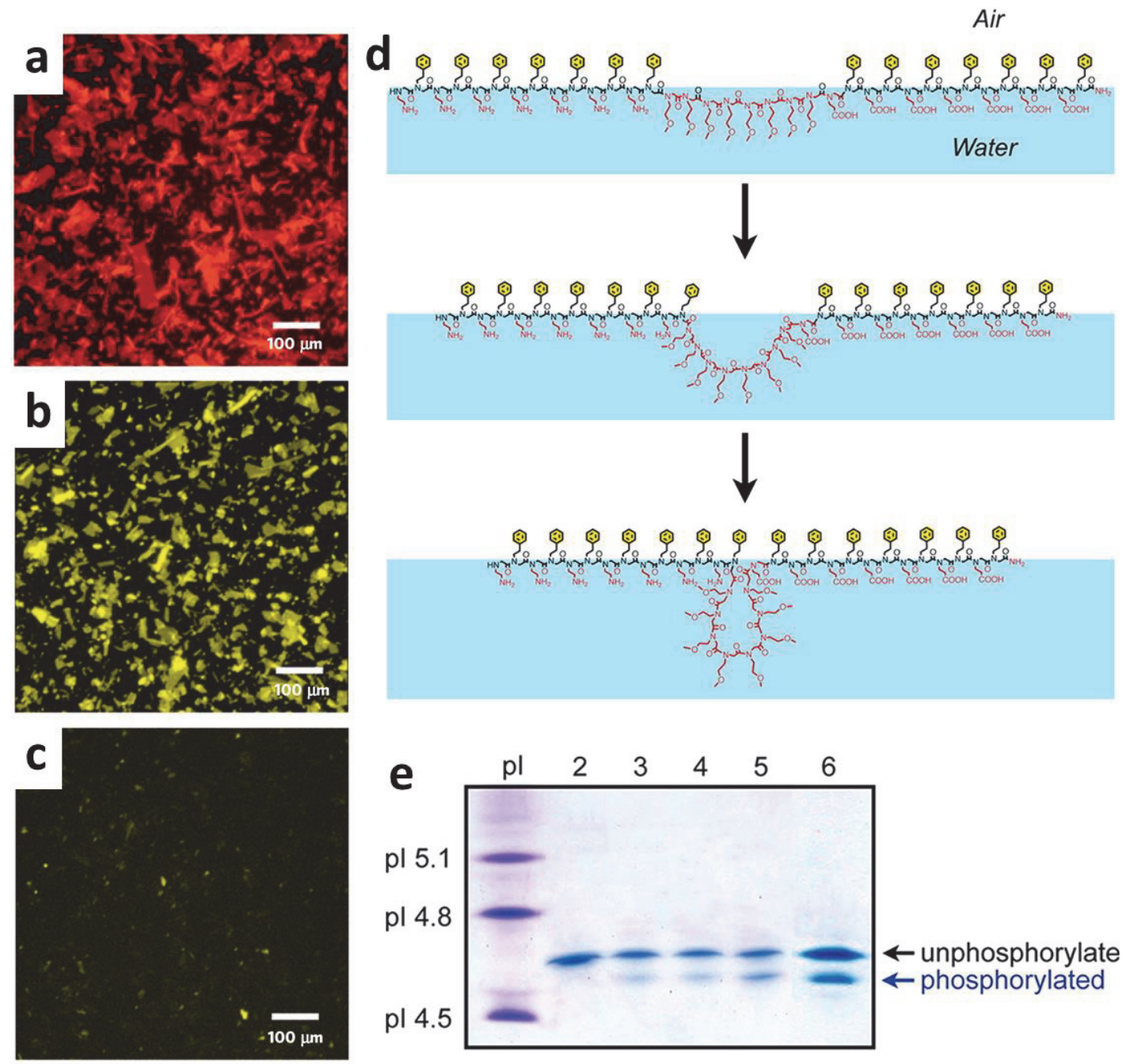

Figure $7 \quad(\mathrm{a} \sim \mathrm{c})$ Specific protein binding to functionalized sheets. (a) Self-assembly with the functionalized peptoid yields a similar population and morphology of nanosheets in comparison to the un-functionalized peptoid as indicated by fluorescence microscopy using Nile Red. (b) Ligand-bearing sheets show a high level of fluorescence after binding to Cy3-streptavidin. (c) Un-functionalized sheets fluoresce very weakly under identical conditions and washes, indicating that binding to the modified sheets are specific. Reproduced with permission from Ref. [49]. Copyright 2010, Nature Publish Group. (d) Mechanism of folding a linear peptoid sequence into a loop domain through compression of the peptoid monolayer at the air-water interface. (e) Isoelectric focusing (IEF) gel electrophoresis used to quantify the degree of phosphorylation of peptide-loop nanosheets by CK2 $\alpha$. Within an IEF gel, peptoid strands are separated based on isolectric point (pI), such that the phosphorylated polymer migrates farther (lower band, more acidic pI) than unphosphorylated starting material (upper band). Lane 1 contains IEF protein standard. Lanes $2 \sim 5$ correspond to $15 \mu \mathrm{g}$ of unstructured peptoid reacted with varying concentration of CK2 $\alpha$. Lane 6 corresponds to peptoid nanosheets reacted with CK2 $\alpha$ under identical conditions as lane 5 . The amount of CK2 $\alpha$ used in lanes $2 \sim$ 6 (with \% conversion to phosphorylated product, listed in parentheses) was: $0 \mu \mathrm{g} \mathrm{CK} 2 \alpha(0 \%$ phosphorylation), $1.0 \mu \mathrm{g}(21 \%), 1.5 \mu \mathrm{g}(24 \%), 2.0 \mu \mathrm{g}(31 \%)$, and $2.0 \mu \mathrm{g}(19 \%)$, respectively. Reproduced with permission from Ref. [58]. Copyright 2013, American Chemical Society.

lamellar stacking of the nanosheets, it is important to note that the disordered arrangement of nanosheets led to a simultaneous increase in both permeance and selectivity (Figure 9c). In another report, Rodenas et al. demonstrated the formation of molecular sieve membranes by the incorporation of $\mathrm{CuBDC}$ nanosheets in a polyimide (PI) matrix at different filler loadings $(2 \sim 12 \mathrm{wt} \%) .{ }^{[64]}$ The resultant composites, denoted as nanoCuBDC(8)@PI, showed outstanding performance for $\mathrm{CO}_{2}$ separation from $\mathrm{CO}_{2} / \mathrm{CH}_{4}$ gas mixtures. Remarkably, at different transmembrane pressure (i.e. $\Delta P=3,4.5,6$ or 7.5 bar), the separation selectivity for nanoCuBDC(8)@PI is 30\% 80\% higher than that for the pure polymeric membrane, and $75 \%$ to eight times higher than that for the bulky-CuBDC(8)@PI coun- terpart in the investigated operating conditions. ${ }^{[64]}$

\section{Outlook and Challenges}

Although much effort has been devoted to the synthesis of free-standing 2D organic or metal-organic materials, their application has been limited due to the less control over their geometric and surface properties. Many reports assumed that the exfoliated nanosheets share the same crystalline structures with their bulk counterparts. In fact, several investigations implied that such assumption might not be true. For example, Chandra et al. ${ }^{[28]}$ investigated the $\mathrm{N}_{2}$ adsorption properties of COF materials (e.g. TpPa- $\mathrm{NO}_{2}$ ) 

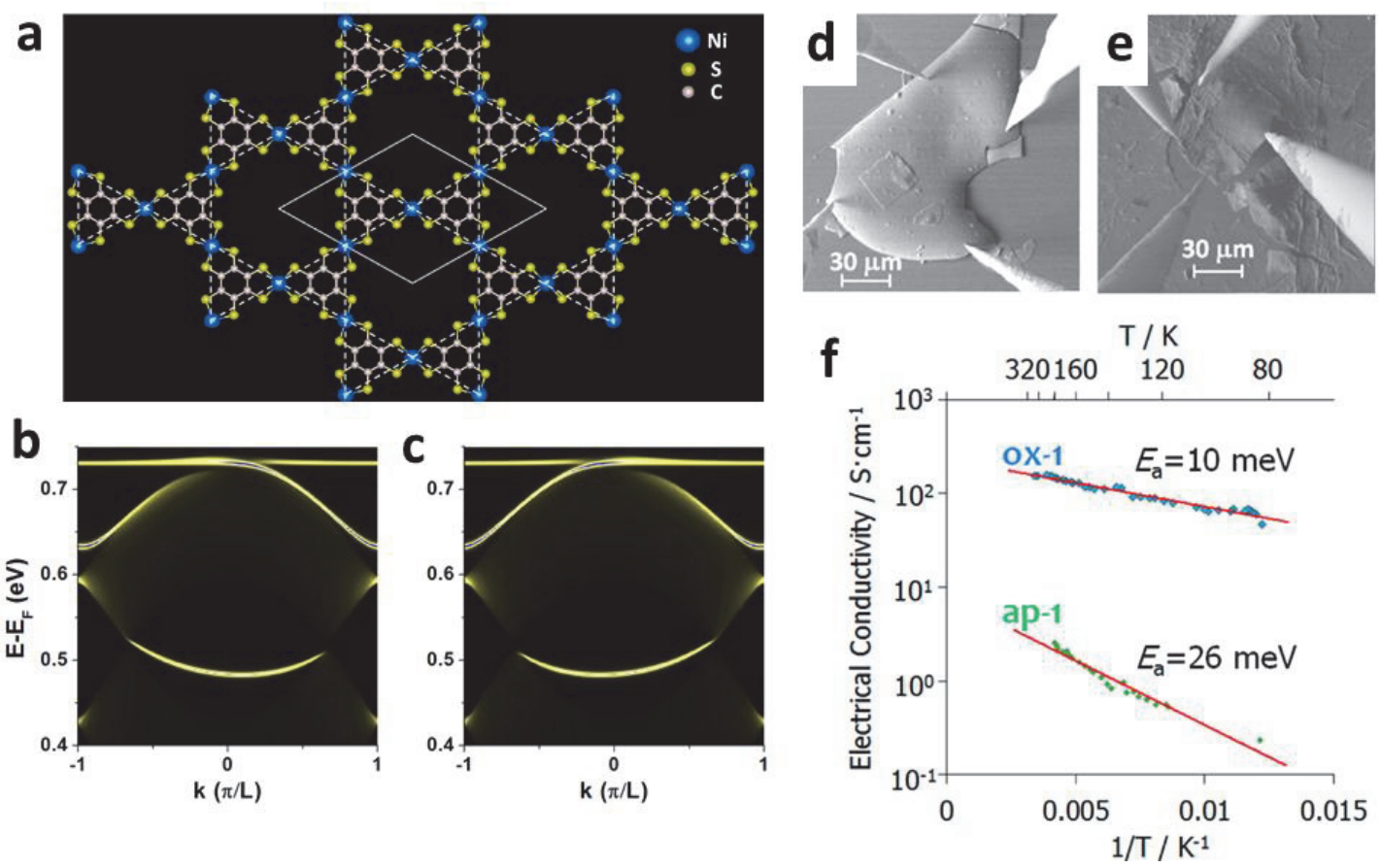

Figure 8 (a) Schematic illustration and chemical structure of monolayer nickel bis(dithiolene) complex nanosheet $(b \sim c)$. The semi-infinite edge states for the (b) spin-up and (c) spin-down components, respectively. Overlapping (b) and (c) would give the 1D edge Dirac band in both SOC gaps. Reproduced with permission from Ref. [61]. Copyright 2013, American Chemical Society $(d \sim e)$. SEM images of the van der Pauw measurement of oxidized nickel bis(dithiolene) complex $\pi$-Nanosheet (ox-1) and as prepared nickel bis(dithiolene) complex $\pi$-Nanosheet (ap-1), respectively. (f) Temperature-dependent electrical conductivity for ox-1 and ap-1. The conductivity contains an error of 10\%. Reproduced with permission from Ref. [62]. Copyright 2014, American Chemical Society
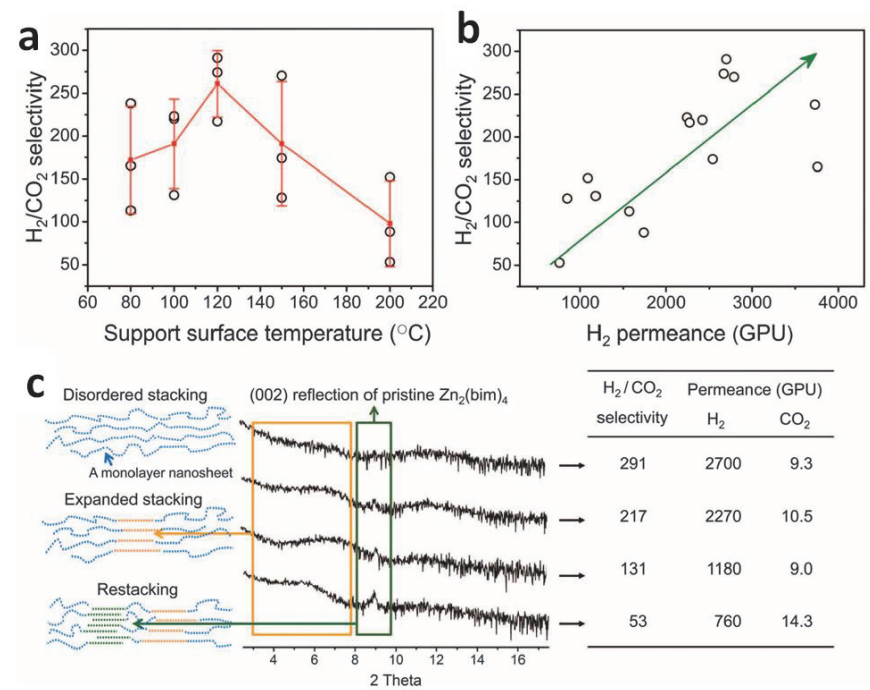

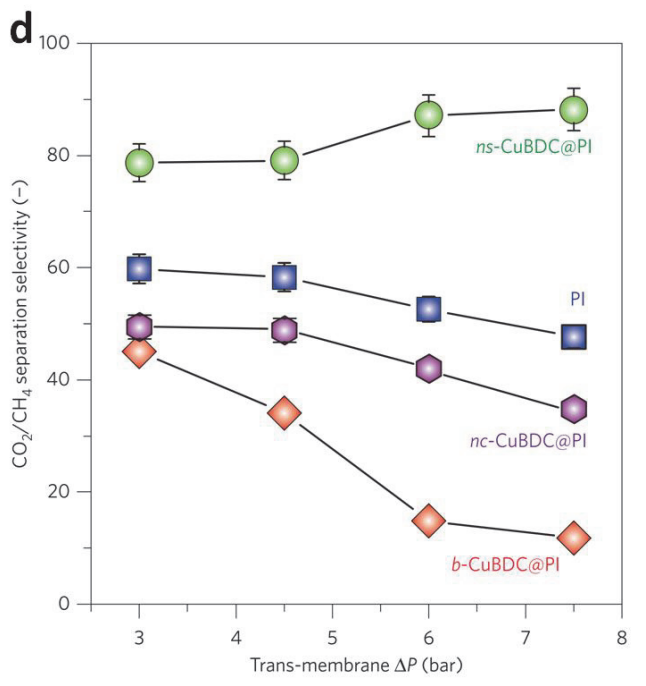

Figure 9 (a) Scatterplot of $\mathrm{H}_{2} / \mathrm{CO}_{2}$ selectivity measured from 15 membranes. The red line with symbols shows the average selectivity and dispersion of selectivity of the membranes prepared at different coating temperatures. (b) Anomalous relationship between selectivity and permeance measured from 15 membranes. (c) Powder XRD patterns of four membranes with different separation properties. The cartoons at the left schematically illustrate the microstructural features of the nanosheet layers. The yellow and green portions correspond to the low-angle humps and the (002) peaks in the XRD patterns, respectively. Reproduced with permission from Ref. [63]. Copyright 2014, American Association for the Advancement of Science. (d) Separation selectivity, defined as the ratio between the permeability of $\mathrm{CO}_{2}$ and $\mathrm{CH}_{4}$, as a function of the pressure difference over the membrane for the MOF-polymer composites when employed as membranes in the separation of $\mathrm{CO}_{2}$ from an equimolar $\mathrm{CO}_{2} / \mathrm{CH}_{4}$ mixture at $298 \mathrm{~K}$. Reproduce with permission from Ref. [64]. Copyright 2015, Nature Publishing Group.

before and after delamination, and found that the surface area of the COF decreased drastically after the exfoliation. They speculated that disorder might have been created in the materials during the delamination which disturbed the long range pore structure of the COFs. However, the study of defects and structural disorders in free-standing ultrathin 
2D organic or metal-organic materials, which is important in many applications, is still challenging. Moreover, their preparation mainly relies on the top-down methods, ${ }^{[12]}$ which, however, usually result in the production of multilayer nanosheets, and hence the development of high-yield single-layer preparation methods requires much more effort and exploration in the future studies.

Compared to the inorganic 2D materials, one important advantage of $2 \mathrm{D}$ organic or metal-organic materials is their ready availability for post-synthetic modification, ${ }^{[10,11]}$ which unfortunately has not been extensively investigated. It is believed that by combining molecular design and synthesis, the highly ordered 2D materials can act as 2D platforms for chemical reactions, to yield versatile hybrid systems for wider applications.

\section{作者简介}

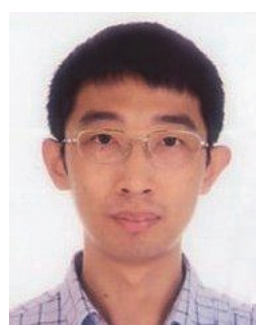

李绍周, 2003 年毕业于华中科技大学, 2004 年硕士研究生 毕业于新加坡国立大学, 2011 年博士研究生毕业于新加坡南 洋理工大学, 2011 2013 年在新加坡南洋理工大学霍风蔚组 进行博士后研究, 2013 年进入南京邮电大学材料科学与工程 学院工作至今. 近期主要从事有机无机杂化材料和二维纳米 材料的研究工作, 致力于纳米材料的制备、表面改性以及器件 化等多个领域的理论和应用的研究. 近五年来在国内外知名 刊物 Nature Chem., Nature Commun., Nano Lett., Adv. Mater. 等 已发表 SCI 研究论文 20 余篇.

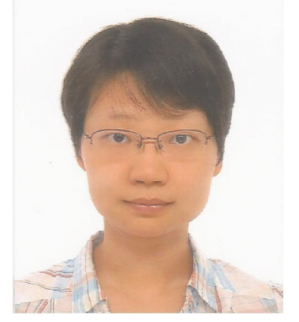

黄晓, 2006 年毕业于新加坡南洋理工大学材料科学与工 程系, 同年留校攻读博士学位师从张华、Freddy Boey 教授, 2011 年获得博士学位随后留校从事博士后研究工作. 2013 年 加入南京工业大学先进材料研究院至今. 主要研究方向是功 能化纳米复合材料, 课题主要包括基于石, 墨烯/金属纳米结构 复合材料的合成、结构研究及应用; 类石墨烯二维纳米材料的 制备、复合及应用. 累计发表了 SCI 论文 50 余篇, 包括 Nature Commun., Chem. Soc. Rev., Angew. Chem. Int. Ed., Adv. Mater. 等. 论文被引用 4000 余次.

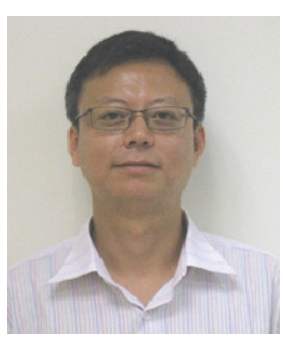

张华教授, 1992 年毕业于南京大学化学系, 1998 年于北京 大学化学系获理学博士学位. 1999 2006 年期间分别在比利 时鲁汶大学、美国西北大学、美国 NanoInk Inc、、新加坡生物 工程与纳米技术研究院从事研究工作. 2006 年起, 在南洋理工 大学材料科学与工程学院从事教学、研究工作. 现为南洋理工 大学教授. 目前担任学术杂志 ACS Nano, Chem. Mater., Small, ACS Appl. Mater. Interfaces, Carbon, Applied Materials Today, Energy Storage Materials, Chinese Science Bulletin, Science China Materials, NANO 编委, 是 Chemical Society Reviews, Nanoscale, Nanoscale Horizons, Materials Research Express, ChemPlusChem 顾问委员会成员. 目前已在Science (1)、Nature Chem. (2)、Nature Commun. (6)、Sci. Adv. (1)、Chem. Soc. Rev. (7)、Acc. Chem. Res. (1)、 J. Am. Chem. Soc. (8)、Angew. Chem. Int. Ed. (21)、Adv. Mater. (23)、ACS Nano (23)、Nano Lett. (12)、 Energy Environ. Sci. (12)、Adv. Energy Mater. (5)等国际权威的 顶尖科学期刊上发表研究论文 330 余篇, 其中 IF $>10$ 的论文 125 篇. 论文被同行引用超过 20000 次, h 因子为 69 .

\section{References}

[1] Novoselov, K. S.; Geim, A. K.; Morozov, S. V.; Jiang, D.; Zhang, Y.; Dubonos, S. V.; Grigorieva, I. V.; Firsov, A. A. Science 2004, 306, 666.

[2] Huang, X.; Tan, C.; Yin, Z.; Zhang, H. Adv. Mater. 2014, 26, 2185.

[3] Xu, M.; Liang, T.; Shi, M.; Chen, H. Chem. Rev. 2013, 113, 3766.

[4] Tan, C.; Zhang, H. Chem. Soc. Rev. 2015, 44, 2713.

[5] Sasaki, T.; Watanabe, M.; Hashizume, H.; Yamada, H.; Nakazawa, H. J. Am. Chem. Soc. 1996, 118, 8329 .

[6] Coleman, J. N.; Lotya, M.; O'Neill, A.; Bergin, S. D.; King, P. J.; Khan, U.; Young, K.; Gaucher, A.; De, S.; Smith, R. J.; Shvets, I. V.; Arora, S. K.; Stanton, G.; Kim, H.-Y.; Lee, K.; Kim, G. T.; Duesberg, G. S.; Hallam, T.; Boland, J. J.; Wang, J. J.; Donegan, J. F.; Grunlan, J. C.; Moriarty, G.; Shmeliov, A.; Nicholls, R. J.; Perkins, J. M.; Grieveson, E. M.; Theuwissen, K.; McComb, D. W.; Nellist, P. D.; Nicolosi, V. Science 2011, 331, 568.

[7] Zeng, Z.; Yin, Z.; Huang, X.; Li, H.; He, Q.; Lu, G.; Boey, F.; Zhang, H. Angew. Chem. Int. Ed. 2011, 50, 11093.

[8] Ma, R.; Liu, Z.; Takada, K.; Iyi, N.; Bando, Y.; Sasaki, T. J. Am. Chem. Soc. 2007, 129, 5257.

[9] Wang, H.; Yu, L.; Lee, Y.-H.; Shi, Y.; Hsu, A.; Chin, M. L.; Li, L.-J.; Dubey, M.; Kong, J.; Palacios, T. Nano Lett. 2012, 12, 4674.

[10] Roy, K.; Padmanabhan, M.; Goswami, S.; Sai, T. P.; Ramalingam, G.; Raghavan, S.; Ghosh, A. Nat. Nanotechnol. 2013, 8, 826.

[11] Gao, M.; Sheng, W.; Zhuang, Z.; Fang, Q.; Gu, S.; Jiang, J.; Yan, Y. J. Am. Chem. Soc. 2014, 136, 7077.

[12] Sakamoto, J.; van Heijst, J.; Lukin, O.; Schlueter, A. D. Angew. Chem. Int. Ed. 2009, 48, 1030.

[13] Ulman, A. Chem. Rev. 1996, 96, 1533.

[14] Govindaraju, T.; Avinash, M. B. Nanoscale 2012, 4, 6102.

[15] Makiura, R.; Motoyama, S.; Umemura, Y.; Yamanaka, H.; Sakata, O.; Kitagawa, H. Nat. Mater. 2010, 9, 565.

[16] Colson, J. W.; Woll, A. R.; Mukherjee, A.; Levendorf, M. P.; Spitler, E. L.; Shields, V. B.; Spencer, M. G.; Park, J.; Dichtel, W. R. Science 2011, 332, 228.

[17] Kambe, T.; Sakamoto, R.; Hoshiko, K.; Takada, K.; Miyachi, M.; Ryu, J.-H.; Sasaki, S.; Kim, J.; Nakazato, K.; Takata, M.; Nishihara, H. J. Am. Chem. Soc. 2013, 135, 2462.

[18] Love, J. C.; Estroff, L. A.; Kriebel, J. K.; Nuzzo, R. G.; Whitesides, 
G. M. Chem. Rev. 2005, 105, 1103.

[19] James, S. L. Chem. Soc. Rev. 2003, 32, 276.

[20] Gallego, A.; Hermosa, C.; Castillo, O.; Berlanga, I.; Gomez-Garcia, C. J.; Mateo-Marti, E.; Martinez, J. I.; Flores, F.; Gomez-Navarro, C.; Gomez-Herrero, J.; Delgado, S.; Zamora, F. Adv. Mater. 2013, $25,2141$.

[21] Li, P.-Z.; Maeda, Y.; Xu, Q. Chem. Commun. 2011, 47, 8436.

[22] Nicolosi, V.; Chhowalla, M.; Kanatzidis, M. G.; Strano, M. S.; Coleman, J. N. Science 2013, 340, 1420.

[23] Nielsen, R. B.; Kongshaug, K. O.; Fjellvag, H. J. Mater. Chem. 2008, 18, 1002.

[24] Feng, X.; Ding, X.; Jiang, D. Chem. Soc. Rev. 2012, 41, 6010.

[25] Berlanga, I.; Luisa Ruiz-Gonzalez, M.; Maria Gonzalez-Calbet, J.; Fierro, J. L. G.; Mas-Balleste, R.; Zamora, F. Small 2011, 7, 1207.

[26] Berlanga, I.; Mas-Balleste, R.; Zamora, F. Chem. Commun. 2012, 48, 7976.

[27] Bunck, D. N.; Dichtel, W. R. J. Am. Chem. Soc. 2013, 135, 14952.

[28] Chandra, S.; Kandambeth, S.; Biswal, B. P.; Lukose, B.; Kunjir, S. M.; Chaudhary, M.; Babarao, R.; Heine, T.; Banerjee, R. J. Am. Chem. Soc. 2013, 135, 17853.

[29] Kissel, P.; Murray, D. J.; Wulftange, W. J.; Catalano, V. J.; King, B. T. Nat. Chem. 2014, 6, 774 .

[30] Kissel, P.; Erni, R.; Schweizer, W. B.; Rossell, M. D.; King, B. T.; Bauer, T.; Goetzinger, S.; Schlueter, A. D.; Sakamoto, J. Nat. Chem. 2012, 4, 287.

[31] Saines, P. J.; Steinmann, M.; Tan, J.-C.; Yeung, H. H. M.; Li, W.; Barton, P. T.; Cheetham, A. K. Inorg. Chem. 2012, 51, 11198.

[32] Saines, P. J.; Tan, J.-C.; Yeung, H. H. M.; Barton, P. T.; Cheetham, A. K. Dalton Trans. 2012, 41, 8585.

[33] Tan, J.-C.; Saines, P. J.; Bithell, E. G.; Cheetham, A. K. ACS Nano 2012, 6, 615 .

[34] Nie, W.-X.; Bao, S.-S.; Zeng, D.; Guo, L.-R.; Zheng, L.-M. Chem. Commun. 2014, 50, 10622.

[35] Araki, T.; Kondo, A.; Maeda, K. Chem. Commun. 2013, 49, 552

[36] Gai, S.; Li, C.; Yang, P.; Lin, J. Chem. Rev. 2014, 114, 2343.

[37] Makiura, R.; Kitagawa, H. Eur. J. Inorg. Chem. 2010, 3715.

[38] Motoyama, S.; Makiura, R.; Sakata, O.; Kitagawa, H. J. Am. Chem. Soc. 2011, 133, 5640 .

[39] Makiura, R.; Konovalov, O. Sci. Rep. 2013, 3, 2506.

[40] Makiura, R.; Usui, R.; Sakai, Y.; Nomoto, A.; Ogawa, A.; Sakata, O.; Fujiwara, A. Chempluschem 2014, 79, 1352.

[41] Zasadzinski, J. A.; Viswanathan, R.; Madsen, L.; Garnaes, J.; Schwartz, D. K. Science 1994, 263, 1726.

[42] Bauer, T.; Zheng, Z.; Renn, A.; Enning, R.; Stemmer, A.; Sakamoto, J.; Schlueter, A. D. Angew. Chem. Int. Ed. 2011, 50, 7879.

[43] Robertson, E. J.; Oliver, G. K.; Qian, M.; Proulx, C.; Zuckermann,
R. N.; Richmond, G. L. Proc. Natl. Acad. Sci. USA 2014, 111, 13284.

[44] Payamyar, P.; Kaja, K.; Ruiz-Vargas, C.; Stemmer, A.; Murray, D. J.; Johnson, C. J.; King, B. T.; Schiffmann, F.; VandeVondele, J.; Renn, A.; Goetzinger, S.; Ceroni, P.; Schuetz, A.; Lee, L.-T.; Zheng, Z.; Sakamoto, J.; Schlueter, A. D. Adv. Mater. 2014, 26, 2052.

[45] Sugiyama, Y.; Okamoto, H.; Mitsuoka, T.; Morikawa, T.; Nakanishi, K.; Ohta, T.; Nakano, H. J. Am. Chem. Soc. 2010, 132, 5946.

[46] Nakano, H. J. Ceram. Soc. JPN 2014, 122, 748.

[47] Eck, W.; Kuller, A.; Grunze, M.; Volkel, B.; Golzhauser, A. Adv. Mater. 2005, 17, 2583.

[48] Junggeburth, S. C.; Diehl, L.; Werner, S.; Duppel, V.; Sigle, W.; Lotsch, B. V. J. Am. Chem. Soc. 2013, 135, 6157.

[49] Nam, K. T.; Shelby, S. A.; Choi, P. H.; Marciel, A. B.; Chen, R.; Tan, L.; Chu, T. K.; Mesch, R. A.; Lee, B.-C.; Connolly, M. D.; Kisielowski, C.; Zuckermann, R. N. Nat. Mater. 2010, 9, 454.

[50] Sanii, B.; Kudirka, R.; Cho, A.; Venkateswaran, N.; Olivier, G. K.; Olson, A. M.; Tran, H.; Harada, R. M.; Tan, L.; Zuckermann, R. N. J. Am. Chem. Soc. 2011, 133, 20808.

[51] Kudirka, R.; Tran, H.; Sanii, B.; Ki Tae, N.; Choi, P. H.; Venkateswaran, N.; Chen, R.; Whitelam, S.; Zuckermann, R. N. Biopolymers 2011, 96, 586.

[52] Hamley, I. W.; Dehsorkhi, A.; Castelletto, V. Chem. Commun. 2013, 49, 1850.

[53] An, Q.; Chen, Q.; Zhu, W.; Li, Y.; Tao, C.-a.; Yang, H.; Li, Z.; Wan, L.; Tian, H.; Li, G. Chem. Commun. 2010, 46, 725.

[54] Baek, K.; Yun, G.; Kim, Y.; Kim, D.; Hota, R.; Hwang, I.; Xu, D.; Ko, Y. H.; Gu, G. H.; Suh, J. H.; Park, C. G.; Sung, B. J.; Kim, K. J. Am. Chem. Soc. 2013, 135, 6523.

[55] Kim, Y.; Kim, H.; Ko, Y. H.; Selvapalam, N.; Rekharsky, M. V.; Inoue, Y.; Kim, K. Chem. Eur. J. 2009, 15, 6143.

[56] Yi, Y.; Fa, S.; Cao, W.; Zeng, L.; Wang, M.; Xu, H.; Zhang, X. Chem. Commun. 2012, 48, 7495.

[57] Xu, J.; Wu, G.; Wang, Z.; Zhang, X. Langmuir 2013, 29, 10959.

[58] Olivier, G. K.; Cho, A.; Sanii, B.; Connolly, M. D.; Tran, H.; Zuckermann, R. N. ACS Nano 2013, 7, 9276.

[59] Qi, X.-L.; Zhang, S.-C. Rev. Mod. Phys. 2011, 83, 1057.

[60] Wang, Z. F.; Liu, Z.; Liu, F. Nat. Commun. 2013, 4, 1471.

[61] Wang, Z. F.; Su, N.; Liu, F. Nano Lett. 2013, 13, 2842.

[62] Kambe, T.; Sakamoto, R.; Kusamoto, T.; Pal, T.; Fukui, N.; Hoshiko, K.; Shimojima, T.; Wang, Z.; Hirahara, T.; Ishizaka, K.; Hasegawa, S.; Liu, F.; Nishihara, H. J. Am. Chem. Soc. 2014, 136, 14357.

[63] Peng, Y.; Li, Y.-S.; Ban, Y.-J.; Jin, H.; Jiao, W.-M.; Liu, Z.-L.; Yang, W.-S. Science 2014, 346, 1356.

[64] Rodenas, T.; Luz, L.; Prieto, G.; Seoane, B.; Miro, H.; Corma, A.; Kapteijn, F.; Llabres, X.; Francesc, X.; Gascon, J. Nat. Mater. 2015, 14,48 . 